\title{
PENYULUHAN TENTANG BAHAYA NARKOBA PADA REMAJA
}

\author{
Fatihatul Hayati \\ Prodi DIII Kebidanan STIKes Baiturrahim Jambi \\ Email: fatihatulhayatianam@gmail.com
}

\begin{abstract}
Adolescence is a transition period where the problem generally is the search for identity. Therefore, it often has the urge to present itself as a separate group. But this encouragement often leads teenagers to serious problems, one of which is drug use. The prevalence of drug abuse in special households is much higher than in general households. This indicates that drug abuse and distribution has its own pockets in society. The level of knowledge of drugs in people who know the dangers of drugs are good enough, but their understanding of drug prevention efforts is still low. Thus, it is necessary to make efforts to communicate, education, and information more optimally, especially in the aspect of strengthening the topic or issue of how to make effective prevention from the threat of drug harm. In Jambi city, there are relatively few drug users among adolescents, namely 29 people for the 10-14 age group and 39 people from the 15-18 age group. Adolescent drug users almost all reside in the work area of the Tahtul Yaman's Public Health Center, 27 people for the 10-14 age group and 38 people for the 15-18 year age group.
\end{abstract}

Keywords: adolescence, drug abuse, education

\begin{abstract}
ABSTRAK
Masa remaja merupakan masa transisi yang mana masalah umumnya adalah pencarian jati diri. Oleh karena itu, seringkali memiliki dorongan untuk menampilkan dirinya sebagai kelompok tersendiri. Namun dorongan ini justru seringkali menjerumuskan remaja pada masalah-masalah yang serius salah satunya adalah penggunaan napza. Angka prevalensi penyalahgunaan narkoba di rumah tangga khusus jauh lebih tinggi dibandingkan di rumah tangga umum. Hal ini mengindikasikan bahwa penyalahgunaan dan peredaran narkoba memiliki kantong-kantong tersendiri di masyarakat. Tingkat pengetahuan narkoba pada orang-orang yang tahu bahaya narkoba telah cukup baik, namun pemahaman mereka dalam upaya pencegahan narkoba masih rendah. Dengan demikian, perlu melakukan upaya komunikasi, edukasi, dan informasi yang lebih maksimal terutama dalam aspek penguatan topik atau isu tentang cara melakukan pencegahan yang efektif dari ancaman bahaya narkoba. Di kota Jambi, pengguna Napza dari kalangan remaja relatif sedikit, yaitu 29 orang untuk kelompok umur 10 - 14 tahun dan 39 orang dari kelompok umur 15 18 tahun. Remaja pengguna Napza hampir seluruhnya bertempat tinggal di wilayah kerja Puskesmas Tahtul Yaman yaitu 27 orang untuk kelompok umur $10-14$ tahun dan 38 orang untuk kelompok umur $15-18$ tahun.
\end{abstract}

Kata Kunci: pendidikan, penyalahgunaan narkoba, remaja 


\section{PENDAHULUAN}

Masa remaja merupakan masa transisi, yaitu suatu fase perkembangan antara masa anak-anak menuju masa dewasa. Masalah utama remaja pada umumnya adalah pencarian jati diri. Mereka mengalami krisis identitas. Hal ini merupakan masalah bagi setiap remaja. Oleh karena itu, seringkali memiliki dorongan untuk menampilkan dirinya sebagai kelompok tersendiri. Namun dorongan ini justru seringkali menjerumuskan remaja pada masalahmasalah yang serius salah satunya adalah penggunaan napza (Sarwono, 2011).

Angka penyalahgunaan pernah pakai narkoba di tingkat rumah tangga cenderung turun dari 2010 ke 2015, tetapi mereka yang setahun pakai cenderung stabil dari $2010 \mathrm{ke}$ 2015. Namun demikian angka prevalensi penyalahgunaan narkoba di rumah tangga khusus jauh lebih tinggi dibandingkan di rumah tangga umum. Hal ini mengindikasikan bahwa penyalahgunaan dan peredaran narkoba memiliki kantongkantong tersendiri di masyarakat. Tingkat pengetahuan narkoba pada orang-orang yang tahu bahaya narkoba telah cukup baik, namun pemahaman mereka dalam upaya pencegahan narkoba masih rendah. Dengan demikian, perlu melakukan upaya komunikasi, edukasi, dan informasi yang lebih maksimal terutama dalam aspek penguatan topik atau isu tentang cara melakukan pencegahan yang efektif dari ancaman bahaya narkoba (BNN, 2015)

Pengguna narkoba rata-rata mengkonsumsi pertama kali pada usia 19 tahun, dengan rentang tertinggi 45 tahun dan terendah 12 tahun. Rerata umur pertama kali pakai narkoba tertinggi ditemukan di Papua Barat (25 tahun), dan terendah di Jambi (15 tahun). Alasan penyalahgunaan narkoba yang paling banyak ditemukan adalah karena ingin mencoba narkoba (65\%), diajak/dibujuk teman (55\%), dan bersenang-senang (19\%). (BNN, 2015)
Berdasarkan survei BNN periode tahun 2011-2016, sikap responden terhadap serangkaian pertanyaan menunjukkan variasi yang lebih rendah untuk temuan 2016 dibandingkan tahun 2011. Di tahun 2011, semua variabel sikap tersebut minimal bernilai 60\%. Di tahun 2016, sikap yang paling dianggap berisiko adalah sikap atas mereka yang merokok, alkohol dan rutin ganja. Untuk merokok, semakin tinggi pendidikan maka semakin besar yang berisiko merokok, yaitu dari $46 \%$ di SMP menjadi $73 \%$ di perguruan tinggi. Pola yang sama juga terlihat pada minum alkohol dan mereka yang rutin mengkonsumsi ganja.

Di kota Jambi, pengguna Napza dari kalangan remaja relatif sedikit, yaitu 29 orang untuk kelompok umur 10 - 14 tahun dan 39 orang dari kelompok umur $15-18$ tahun. Remaja pengguna Napza hampir seluruhnya bertempat tinggal di wilayah kerja Puskesmas Tahtul Yaman yaitu 27 orang untuk kelompok umur 10 - 14 tahun dan 38 orang untuk kelompok umur 15 18 tahun (Dinkes Kota Jambi, 2017)

Berdasarkan uraian latar belakang diatas jelas bahwa hal ini sangat memprihatinkan. Untuk itu perlu suatu upaya untuk mencegah bertambahnya kasus penyalahgunaan narkoba di kalangan remaja. Salah satunya dengan cara meningkatkan pengetahuan dan sikap para remaja terhadap narkoba melalui peran aktif bimbingan konseling dan penyuluhan.

\section{TARGET DAN LUARAN}

1. Target

Target dalam kegiatan pengabdian kepada masyarakat ini adalah remaja di wilayah kerja Puskesmas Tahtul Yaman Kota Jambi

2. Luaran

Adapun luaran kegiatan pengabdian ini selain publikasil pada jurnal ilmiah yaitu:

1) Pengertian narkoba 
2) Bahaya penyalahgunaan narkoba

3) Upaya remaja menghindari penyalahgunaan narkoba

4) Upaya mensosialisasikan kepada remaja lain dan membantu memotivasi remaja lain untuk menghindari penyalahgunaan narkoba.

\section{METODE PELAKSANAAN}

Kegiatan Pengabdian kepada masyarakat dilaksanakan pada bulan Mei - Agustus 2017 dengan sasaran kegiatan adalah remaja khususnya siswa SMP Negeri 13 Kota Jambi.

Tahapan kegiatan pengabdian kepada masyarakat meliputi :

Persiapan

1. Sosialisasi : Pertemuan dengan Kepala sekolah dan Petugas Kesehatan di Puskesmas.

2. Mengidentifikasi masalah

3. Perumusan solusi : memberikan pendidikan kesehatan kepada siswa

Pelaksanaan
1. Melakukan pretest (menggali pemahaman siswa tentang penyalahgunaan narkoba).

2. Memberikan pendidikan kesehatan tentang penyalahgunaan narkoba

\section{HASIL DAN PEMBAHASAN}

Kegiatan penyuluhan ini bertujuan agar remaja memahami tentang penyalahgunaan narkoba dan upaya menghindari penyalahgunaan narkoba.

Kegiatan hari pertama adalah melakukan pendidikan kesehatan berupa penyuluhan tentang narkoba yang meliputi Definisi, jenis-jenis, Gejala-gejala penyalahgunaan narkoba. Siswa cukup memahami dan sangat antusias dalam kegiatan ini, terbukti beberapa warga bertanya khususnya tentang jenis-jenis narkoba.

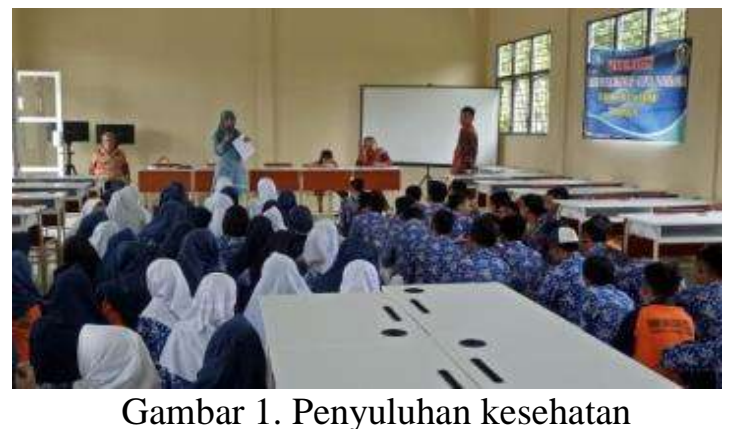

Hari kedua tim melakukan pendidikan kesehatan lanjutan tentang upaya menghindari penyalahgunaan narkoba. Siswa terlihat antusias dilihat dari semangat menjawab pertanyaan dan aktif bertanya serta mampu memberi contoh bentuk kegiatan yang dapat menjadi alternatif dalam menghindari diri dari jeratan narkoba.

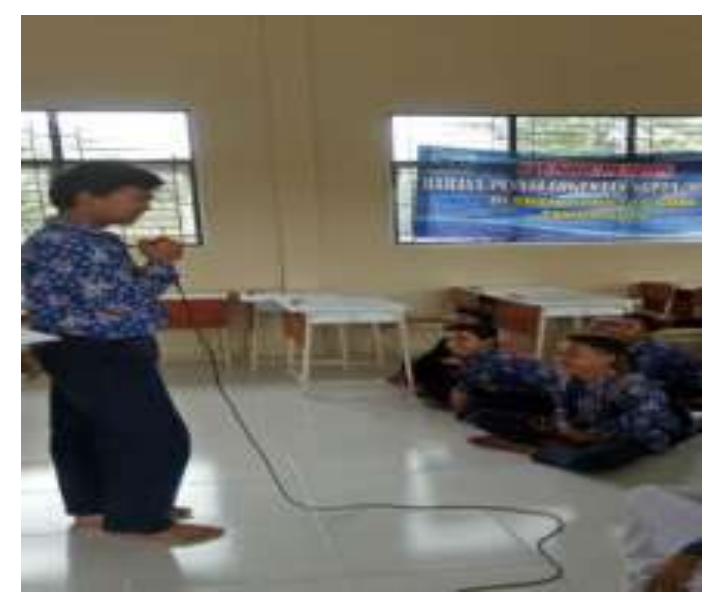

Gambar 2. Salah satu siswa menjelaskan contoh kegiatan upaya menghindari penyalahgunaan narkoba

\section{KESIMPULAN DAN SARAN}

\section{Kesimpulan}

Pelaksanaan pengabdian masyarakat yang dilakukan oleh dosen STIKBA tentang penyuluhan bahaya narkoba di SMP Negeri 13 Kota Jambi berjalan dengan lancer dan didukung penuh oleh pihak sekolah. Remaja paham akan bahaya narkoba dan termotivasi untuk menghindari penyalahgunaan narkoba. 


\section{Saran}

1. Melakukan kegiatan secara rutin agar remaja semakin sadar dan peduli akan bahaya narkoba.

2. Menyelenggarakan kegiatan yang sesuai dengan usia remaja sehingga dapat menjadi wadah penyaluran bakat dan mengisi waktu luang remaja yang bermanfaat.

3. Mengajukan kepada institusi pendidikan perguruan tinggi agar dapat mengatur jadwal kegiatan pengabdian masyarakat dengan mengajak mahasiswa dalam kegiatan penyuluhan.

\section{UCAPAN TERIMAKASIH}

Ucapan terimakasih Kami sampaikan kepada Sekolah Tinggi Ilmu Kesehatan Baiturrahim yang telah menfasilitasi kegiatan ini, kepada Bapak Kepala SMP 13 beserta jajarannya yang banyak membantu kegiatan ini dan Puskesmas Taktul Yaman serta semua pihak yang telah membantu kegiatan Pengabdian kepada Masarakat ini.

\section{DAFTAR PUSTAKA}

BNN. 2015. Survei Prevalensi Penyalahgunaan Narkoba pada Kelompok Rumah Tangga di 20 Provinsi Tahun 2015

BNN, 2015. Ringkasan Eksekutif Hasil Survei BNN Tahun 2016 Puslitdatin BNN

Dinkes Kota Jambi. 2017. Laporan Kesehatan Remaja Propinsi Jambi Tahun 2017

Sarwono. 2011. “Ilmu Kandungan”. PT. Bina Pustaka Sarwono Prawirohardjo. Jakarta 